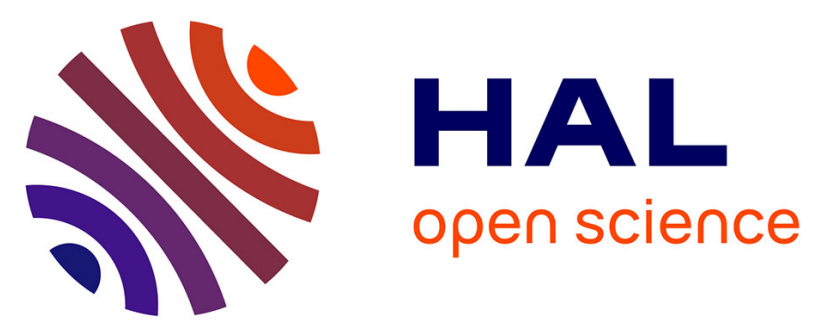

\title{
Evaluation of hepatic iron concentration heterogeneities using the MRI R2* mapping method
}

Jean Mazé, Guillaume Vesselle, Guillaume Herpe, Samy Boucebci, Christine Silvain, Pierre Ingrand, Jean-Pierre Tasu

\section{- To cite this version:}

Jean Mazé, Guillaume Vesselle, Guillaume Herpe, Samy Boucebci, Christine Silvain, et al.. Evaluation of hepatic iron concentration heterogeneities using the MRI R2* mapping method. European Journal of Radiology, 2019, 116, pp.47 - 54. 10.1016/j.ejrad.2018.02.011 . hal-03484362

\section{HAL Id: hal-03484362 https://hal.science/hal-03484362}

Submitted on 20 Dec 2021

HAL is a multi-disciplinary open access archive for the deposit and dissemination of scientific research documents, whether they are published or not. The documents may come from teaching and research institutions in France or abroad, or from public or private research centers.
L'archive ouverte pluridisciplinaire HAL, est destinée au dépôt et à la diffusion de documents scientifiques de niveau recherche, publiés ou non, émanant des établissements d'enseignement et de recherche français ou étrangers, des laboratoires publics ou privés.

\section{(ㄷ)(1) $\$$}

Distributed under a Creative Commons Attribution - NonCommercial| 4.0 International 
\[ \text { Abbreviated Title Page } \]
Manuscript title:
Evaluation of hepatic iron concentration heterogeneities using the MRI R2* mapping method

Manuscript type:

Original Research

\begin{abstract}


Objective: To measure hepatic iron concentration (HIC) heterogeneities using a magnetic resonance $\mathrm{R} 2 *$ mapping method.

Patients and Methods: Ninety-four patients with suspected hepatic iron overload and 10 volunteers were included prospectively. A multi-echo R2* sequence with fat saturation and with three post-processing fitting methods (a single exponential decay model with or without truncation, SED and SEDt, and a constant offset model, COS) was compared to a signal intensity ratio method (SIR), considered as the reference. HIC heterogeneity was evaluated from R2* mapping after placing a ROI on each liver segment.

Results: A strong linear correlation between SIR and R2* methods using the SEDt and COS models was observed ( $\mathrm{r}=0.973$ and 0.955 , respectively). Volunteers and patient liver variabilities, quantified by mean intra-liver standard deviation (SD) were $1.58 \mu \mathrm{mol} / \mathrm{g}$ (mean range $5.06 \mu \mathrm{mol} / \mathrm{g}$ ) and $4.73 \mu \mathrm{mol} / \mathrm{g}$ (mean range $19.08 \mu \mathrm{mol} / \mathrm{g}$ ), respectively. For the patient group, the highest HIC was observed in the IV ${ }^{\text {th }}$ segment. Heterogeneity increased for patients with an $\mathrm{HIC}>60 \mu \mathrm{mol} / \mathrm{g}$ (mean intra-liver $\mathrm{SD}=13.90 \mu \mathrm{mol} / \mathrm{g}$; mean range $=50.60 \mu \mathrm{mol} / \mathrm{g}$ ).

Conclusion: This study is the first to demonstrate in vivo HIC heterogeneities using wholeliver mapping analysis. These preliminary results require confirmation through further studies, but might be useful in cases of single ROI analysis.

Highlights: 
The variability of intra-hepatic iron concentrations can be evaluated using a MR T2* relaxometry method.

Hepatic iron concentration seems to be higher in the $\mathrm{IV}^{\text {th }}$ segment in cases of higher iron deposition, and variability of the hepatic iron load increases with iron content.

To measure liver iron load, a ROI could be placed in segment IV, and not, as in current practice, in the right liver.

Key Words: iron, liver, MRI, quantification, R2* mapping 


\section{ABBREVIATIONS}

ROI $=$ region of interest

MRI= magnetic resonance imaging

$\mathrm{HIC}=$ hepatic iron concentration

SED= single exponential decay model without truncation,

SEDt $=$ single exponential decay model with truncation,

COS $=$ constant offset

$\mathrm{SIR}=$ signal intensity ratio

$\mathrm{TE}=$ time of echo

FIESTA= Fast Imaging Employing Steady-state Acquisition

SD= standard deviation 


\section{INTRODUCTION}

Magnetic resonance imaging (MRI) is currently the most widely available technique used to evaluate liver iron load [1]. The underlying mechanism is that the MR relaxation time of hydrogen nuclei decreases with increasing amounts of iron. Two main techniques have been developed, both of which are based-on $\mathrm{T} 1, \mathrm{~T} 2$, and $\mathrm{T} 2 *$ relaxation time shortening if there is iron content in the liver:; $1-$ a semi-quantitative method, using a signal intensity ratio (SIR) from a region of interest (ROI) between the liver and a reference tissue that does not accumulate iron (commonly the paraspinous muscles). This method is well-established and reproducible [2] and studies have demonstrated its robustness versus liver biopsies, the gold standard method; and 2-a quantitative method that measures $\mathrm{T} 2 *$ (or less frequently T2) decay rates using various echo times [3]. As $\mathrm{T} 2 *$ has a negative relationship with hepatic iron concentration (HIC), it is commonly converted into R2* according to the relationship R2*= 1000/T2*; thus, the relaxation rate becomes directly proportional to HIC. T2* measurements can be obtained from signal averages in the ROI or on a pixel-by-pixel basis, which results in liver iron overload maps [4]. This second technique presents different limitations due to a lack of standardization of the different models used for $\mathrm{T} 2 *$ curve-fitting and for the applied echo times (TEs). In addition, a quick decrease in the $\mathrm{T} 2 *$ signal leads to an underestimation of iron quantification, particularly in cases of high HIC [5].

There are only a few studies comparing the accuracy of the two MR methods [6-8] and the impact of the different post-processing procedures of the $\mathrm{R} 2 *$ method $[9 ; 10]$. In addition, to date, only one team has studied hepatic iron heterogeneity and those authors failed to demonstrate any variation on MRI, although this has been proven by pathological results [11]. Therefore, the purpose of this study was to evaluate HIC liver heterogeneities from T2* mapping measurements. The different post-processing models used for $\mathrm{T} 2 *$ measurements were first compared with the SIR method used as the gold standard method. 


\section{MATERIALS AND METHODS}

\section{Patients}

Over a nineteen-month period (November 2014 to May 2016), all patients who were referred for suspicion of liver iron overload and who were scheduled for a MRI examination were included prospectively. Laboratory tests were performed, at most, 10 days after the MRI examination, including a serum dosage of ferritin and an evaluation of the transferrin saturation coefficient. For patients with suspected genetic disease, a search for the C282Y and H63D mutations was performed. Noninvasive liver fibrosis tests were performed to quantify fibrosis (fibroscan ${ }^{\circledR}$ and Fibrotest ${ }^{\circledR}$ ). All included patients gave their written, informed consent to participate. The local ethics committee approved the study. The privacy rights of human subjects were observed in agreement with the local laws. A group of 10 volunteers was also included. They had no history of hepatic, immunologic, or viral disease nor were they taking any medication for a genetic disease.

\section{MRI techniques and image analysis}

All examinations were performed on a 1.5 Tesla optima MR 450w (General Electric Healthcare, Milwaukee, USA). The protocol systematically included axial slice morphological sequences, T2 FIESTA (Fast Imaging Employing Steady-state Acquisition) and T1 in/out phases (TE $4.2 \mathrm{~ms}$ and $2.1 \mathrm{~ms}$, respectively).

To quantify HIC using the SIR method, the Rennes University protocol proposed by Gandon et al. [12], including a T1-weighted gradient echo sequence $(\mathrm{TR}=120 \mathrm{~ms} ; \mathrm{TE}=4 \mathrm{~ms} ; \mathrm{FA}=$ 
$\left.90^{\circ}\right)$ and four T2-weighted breath-hold gradient echo sequences $(\mathrm{TR}=120 \mathrm{~ms}$; multiple $\mathrm{TE}=$ 4, 9, 14, $21 \mathrm{~ms} ; \mathrm{FA}=20^{\circ}$, was used.

To quantify HIC using the R2* method, a fat-saturated multi-gradient echo sequence with 12 echo times $(\mathrm{TE}$ initial $=1.4 \mathrm{~ms} ;$ TE final $=22.4 \mathrm{~ms} ;$ delta $\mathrm{TE}=1.9 \mathrm{~ms} ; \mathrm{TR}=51.3 \mathrm{~ms} ; \mathrm{FA}=$ $25^{\circ} ;$ matrix $=224 \times 160$ pixels; $\left.\mathrm{NEX}=1 ; \mathrm{FOV}=42 \times 31.5 \mathrm{~cm}\right)$ was used. During one breathhold of 16 seconds, four axial hepatic slices were acquired, with a thickness of $8 \mathrm{~mm}$ every 10 $\mathrm{mm}$, to cover each liver segment.

\section{Post-processing}

1-To quantify SIR for each sequence, three regions of interest (ROI) that contained at least 100 pixels in the right hepatic lobe and two ROIs in the paraspinous muscles on the same axial slice (total number of regions of interest $=25$ ) were drawn. The signal intensity of each ROI was then used to obtain the HIC from the dedicated Rennes University website (http://www.radio.univ-rennes1.fr/Sources/FR/HemoCalc15.html).

2-For R2* quantification, three image analyses were performed.

First, a single ROI was placed on the right liver (at least $100 \mathrm{~mm}^{2}$ ), in a vessel-free area, avoiding other sources of artefacts (i.e., motion). Estimation of R2* values was performed by fitting the R2* signal using three decay models: a single exponential decay model, SED $(a)$, and a single exponential decay model with truncation method, SEDt $(b)$. Later echo times were manually excluded so as to limit noise effects at low $\mathrm{T} 2 *$ values. The third decay model was also applied using a constant offset, $\operatorname{COS}(c)$. 
Second, a multi ROI analysis was performed to evaluate the heterogeneous deposition of iron. A ROI with at least 100 pixels was drawn in each hepatic segment, determined according to the Couinaud classification [13]. The ROI was placed in the area of homogeneous liver on the $\mathrm{T} 2 *$ images. Considering the relatively lower signal-to-noise ratio and the influence of inferior vena cava movements, segment I was excluded from the analysis. Two ROIs were positioned in segment IV, one at the upper part (IVa) and the other at the lower part (Ivb), giving a total number of eight ROIs (Fig. 1).

Finally, a whole-liver ROI was obtained by contouring the whole liver on four axial slices, excluding major vessels. Within this large ROI, two ROIs were drawn, one in the area that showed the lowest HIC, the second in area that showed the highest HIC according to the T2* colour maps. The HIC range was computed from the difference between the highest and the lowest values. For the multi-ROI approach, the signal was fitted by a single exponential equation with a constant offset model (COS).

All R2* values from the single ROI analysis were correlated with HIC using the SIR method. SIR and R2* relaxometry methods were also compared after transformation according to the Wood's calibration algorithm when the COS method was used: Fe $(\mathrm{mg} / \mathrm{g})=0.0254 \times \mathrm{R} 2 *+$ 0.202 [14]. For other R2* relaxometry methods, a second linear regression model was used: $\mathrm{Fe}(\mathrm{mg} / \mathrm{g})=0.02876 \times \mathrm{R} 2 *+0.137$ [3]. For both, the HIC was converted into units of $\mu \mathrm{mol} / \mathrm{g}$ using the following formula: $\mathrm{Fe}(\mathrm{mg} / \mathrm{g})=55.845 \times 10^{-3} \times \mathrm{Fe}(\mu \mathrm{mol} / \mathrm{g})$.

To compare SIR and R2*, three iron levels were used [12]: no iron overload $(<36 \mu \mathrm{mol} / \mathrm{g})$; mild iron overload (36 - $100 \mu \mathrm{mol} / \mathrm{g}$ ); and high iron overload (> $100 \mu \mathrm{mol} / \mathrm{g}$ ). 
To evaluate liver heterogeneity from R2* mapping, four groups were defined according to R2* measures: group 1 with no iron overload ( $\mathrm{HIC}<36 \mu \mathrm{mol} / \mathrm{g}$ ); group 2 with a mild iron overload (36 < HIC < $60 \mu \mathrm{mol} / \mathrm{g}$ ); group 3 with an iron overload higher than $60 \mu \mathrm{mol} / \mathrm{g}$; and group 4, which comprised the 10 volunteers. The mean intra-liver standard deviation (SD) and the mean range between the subgroups were compared.

Hepatic fat content was estimated based on chemical shift imaging (CSI) using T1-weighted in- and opposed-phase gradient-recalled echo (GRE) MRI sequences and the following formula: Fat fraction $(\mathrm{FF})=100 \mathrm{x}($ signal IP - signal OP) $/ 2 \mathrm{x}$ signal IP [15]. Fat content was considered significant if the FF was over $5 \%$.

\section{Statistical analysis}

Intra-liver standard deviation (SD) was extracted for each sub-group. Mean intra-liver SD and the mean range were compared between the sub-groups. A linear regression model was fitted to the patient data to assess the relationship between HIC and the R2* signal. Agreement between the SIR method and T2* relaxometry was assessed by Bland Altman plots. The Kolmogorov-Smirnov test was used to assess the normality of distribution parameters. In case of deviation from the normality assumption, a logarithmic transformation was performed. Correlation between parameters was analysed using Pearson' r-correlation coefficients. A two-way analysis of variance (ANOVA) with logarithmic transformation was used to compare HIC between segments. A $p$ value less than 0.05 was considered statistically significant. Statistical computations used SAS V9.4 and Prism V5 computer software. 


\section{RESULTS}

\section{Patients and serum ferritin}

Ninety-four patients (M/F: 69/25; mean age: 54.5 +/- 14.1-year-old) and 10 volunteers (M/F: 7/3; mean age: $28.2+/-8.2$ year-old) were included during the study period. The diseases that caused iron overload were dysmetabolic hepatosiderosis syndrome $(\mathrm{N}=54)$, hereditary hemochromatosis $\mathrm{C} 282 \mathrm{Y}+/+$ or $\mathrm{H} 63 \mathrm{D}+/+(\mathrm{N}=6)$, acute leukemia $(\mathrm{N}=4)$, double heterozygous mutation $\mathrm{C} 282 \mathrm{Y}+/-$ and $\mathrm{H} 63 \mathrm{D}+/-(\mathrm{N}=3)$, sickle cell disease $(\mathrm{N}=3)$, thalassemia $(\mathrm{N}=2)$, and Gilbert's disease $(\mathrm{N}=1)$. The cause of hyperferritinemia remained unknown for 21 patients at the time of study analysis. Fifty-five patients were assessed for fibrosis stage with noninvasive tests. Sixteen subjects (29\%) had significant fibrosis (stage greater than F2). Laboratory tests were performed for 78 patients $(83 \%)$ at a delay of less than two months from the MR examination. Serum ferritin ranged from 13 to $3876 \mathrm{ng} / \mathrm{mL}$ (mean $=818.3+/-$ $597.4 \mathrm{ng} / \mathrm{mL}$ ). Fat fraction ranged from 7 to $48 \%$ (mean=21.3\%). Forty-four of 94 patients (47\%) had fatty liver disease according to the 5\% MR criterion $(\mathrm{M} / \mathrm{F}=37 / 7)$.

\section{Single ROI analysis}

For the patient group, mean hepatic iron concentration using the SIR method was $76.44+/-$ $59.69 \mu \mathrm{mol} / \mathrm{g}$ (ranging from 5 to $350 \mu \mathrm{mol} / \mathrm{g}$ ). Mean hepatic R2* using SED, SEDt, and COS models was $69.3+/-22.8 \mathrm{~Hz}, 80.8+/-50.7 \mathrm{~Hz}$, and $95.4+/-62.4 \mathrm{~Hz}$, respectively. Table 1

gives the main results. A strong linear relationship was observed between the SIR method 
and the $\mathrm{R} 2 *$ transverse relaxation rate using the truncation and offset decay models (Fig. 3). The SED model, however, was weakly correlated to the SIR results $(r=0.657)$.

Table 2 and Figure 4 show the main results for the comparison of the SIR and R2* methods in the entire cohort. The two methods gave discordant results when stratifying the HIC according to the three levels of iron content defined for this study.

\section{Multi-ROI analysis}

\section{Segmental variability}

Table 3 provides the main results.

For volunteers, the HIC multi-ROI ranged from $-4.73 \%$ (seg IVb) to $+5.30 \%$ (seg VIII). Intraliver variability, quantified by mean intra-liver SD and mean range, was $1.58 \mu \mathrm{mol} / \mathrm{g}(\mathrm{CV}=$ $6.4 \%)$ and $5.06 \mu \mathrm{mol} / \mathrm{g}$, respectively.

In the patient group, eight were excluded $(\mathrm{N}=86)$ from the multi-ROI analysis because the four axial slices did not include all hepatic segments. The mean multi-ROI HIC (50.09 +/$35.02 \mu \mathrm{mol} / \mathrm{g})$ and the mean single-ROI HIC $(48.38+/-29.33 \mu \mathrm{mol} / \mathrm{g})$ were significantly different $(\mathrm{p}=0.0471)$. For ANOVA analysis, the highest iron concentration was observed in the IVa segment $(52.60 \mu \mathrm{mol} / \mathrm{g})$. The mean iron concentration in segment VIII was significantly higher than the mean HIC in segments III and VI. The lowest HIC was in segment VI. Nineteen patients (22\%) had simultaneous segments with no iron overload and mild iron overload. Three patients had segments with mild and moderate iron overload. Two patients had segments with moderate and high iron overload. Figure 2 illustrates a case of HIC heterogeneities. 
In the sub-group of patients with significant fatty liver content, iron concentrations were 38.48 $+/-11.94 \mu \mathrm{mol} / \mathrm{g}$ and $38.00+/-11.66 \mu \mathrm{mol} / \mathrm{g}$, respectively, for the mean HIC single-ROI and the mean HIC multi-ROI methods (not significantly different). The highest iron concentration was detected in segment IVa, followed by segment VIII, as in the entire patient cohort.

In a group that included 18 patients with moderate-to-high overload according to the SIR method (> $100 \mu \mathrm{mol} / \mathrm{g}$; mean SIR method $=167.78 \mu \mathrm{mol} / \mathrm{g}$ ), the mean HIC single-ROI was $87.93+/-42.31 \mu \mathrm{mol} / \mathrm{g}$ and the mean HIC multi-ROI was $95.13+/-54.56 \mu \mathrm{mol} / \mathrm{g}$. The highest mean segmental iron concentration was detected in segment IVb and the lowest mean in segment VII. The ANOVA test found significant segmental variability (Fig. 6). The mean HIC in segments IVa, IVb, and VIII was significantly higher than the mean HIC in the other segments, except for segments II and V. The percentage of deviation of the segments from the mean HIC multi-ROI ranged from $-10.43 \%$ (seg VII) to $+6.79 \%$ (seg IVb). The mean intraliver SD was $12.44 \mu \mathrm{mol} / \mathrm{g}$ and the mean range was $46.07 \mu \mathrm{mol} / \mathrm{g} . \mathrm{CV}=13.1 \%$.

In the sub-group of patients with significant fibrosis $(\mathrm{N}=16)$, there was no significant segmental variability $(\mathrm{p}=0.171)$.

\section{Intra-liver variability: analysis of $\mathbf{R} 2 *$ mapping (Table 4)}

For this analysis, group 1 included 43 patients with no iron overload (mean age: $52.5+/-13.1$ year-old), group 2 were patients with mild iron overload (36 patients, mean age: $51.0+/-$ 11.1-year-old), group 3 were patients with an iron overload of $>60 \mu \mathrm{mol} / \mathrm{g}$ ( 15 patients, mean 
age: $55.5+/-12.7$-year-old), and the 10 volunteers (group 4). Eight patients were excluded from group 1 (multi-ROI analysis not feasible, $\mathrm{N}=35$ ). Significant differences $(\mathrm{p}<0.0001)$ were found between each group. Mean intra-liver SDs between the sub-groups were significantly different, except between group 1 and group 4 . The mean ranges between them were likewise significantly different. The highest mean intra-liver SD and range were detected in group 3.

\section{DISCUSSION}

While heterogeneity in iron liver overload is well known by pathologists, this study is the first to quantify it in vivo from liver R2* mapping. For this purpose, we used a specific fitting that seems accurate compared to the SIR method, and two parameters: intra-liver SD, and the range reflecting heterogeneity. Heterogeneity seems to be higher in the $\mathrm{IV}^{\text {th }}$ segment in cases of higher iron deposit. In addition, variability of the iron hepatic load increases with iron content.

The heterogeneity of iron deposition has been demonstrated in different histological studies through multiple biopsies from liver transplants [16-18]. Coefficients of variation ranged from 7 to $80 \%$ and Edmond et al. observed that the SD was significantly correlated with the mean HIC [18]. What remains under discussion is the pattern of this heterogeneity. In a study by Ambu et al., [19], a preferential subcapsular accumulation was shown, and the highest iron concentrations were detected in the left lobe. However, liver biopsies provide only local sample estimates, and multiple biopsies are not applicable in clinical practice. 
Multiple ROI methods or whole-liver analysis can be achieved by R2* mapping, which is accurate compared to the other widely used MR method, SIR $[2 ; 3 ; 14 ; 20 ; 21]$. To our knowledge, there have been only two previous studies on in vivo liver iron heterogeneities using R2* imaging [11; 22]. In the first [11], Meloni et al. observed greater segmental variability in the healthy group with no iron liver overload, although, for moderate and high iron hepatic overload, variability was considered negligible. The authors explained these paradoxical results by magnetic susceptibility effects that accelerate $\mathrm{T} 2 *$ decay. The authors consequently proposed an algorithm to correct these susceptibility effects, which led to complete disappearance of all heterogeneities in patients and volunteers. In our healthy group, it is interesting to note that, as in the study by Meloni et al., the highest variation of HIC was found in segment VIII, followed by segment VII. But, in our study, the variations around the mean measurements were 4 to 5 times lower: $-4.7 \%$ to $+5.3 \%$ compared to $-22.9 \%$ to + $19.8 \%$, respectively. Due to the high level of variations, Meloni et al. had to use susceptibility corrections. Conversely, our lower level of variation allowed us to apply our data without any filtration.

The second study, by Sofue et al., was centered on the reproducibility of measurements of fat fraction and iron content from R2* measurements. The authors also described small but significant variability in $\mathrm{R} 2 *$ measurements in different hepatic segments. However, the study was designed to measure only a limited number of liver segments and heterogeneity in the whole liver was not evaluated [22].

A major confounder of $\mathrm{R} 2 *$ measurements is the presence of fat, which introduces sinusoidal modulations in signal evolution [5; 23]. These modulations arise from the different resonance frequencies for water and lipid protons, which can affect R2* evaluation. Different post- 
processing techniques [24-26] have been proposed, such as acquisition of echo when fat and water components are approximately in-phase (TE increments of approximately $2 \mathrm{~ms}$ at 1.5T). However, this approach could be hampered by fat-fat signal interferences that limit its application in cases of high HIC. To avoid fat-water modulations, fat suppression (FS) techniques were also used $[27 ; 28]$, as in this work. However, both methods, in-phase acquisition and FS, might have limited application in high HIC, given that the accessible temporal range in which to evaluate fat-water modulations is restricted due to rapid signal decay [5].

In this study, the hepatic fat fraction was estimated according to CSI FF, using T1-weighted in- and opposed-phase GRE MRI sequences, the technique most commonly used in liver MR imaging [29]. There are other methods, such as spectroscopy, the reference method, which is more complex to perform routinely, and the CSI fat fraction corrected to the spleen according to Koelblinger et al. [30]. The correction provided better correlations than CSI FF on a small cohort of 35 patients, at $3 \mathrm{~T}$ with no cases of iron overload. However, in a dysmetabolic syndrome population, such as the one in our study, in which iron deposits into the spleen are frequent, this correction should not be performed.

To evaluate liver iron content, a 3D multiecho Dixon MR sequence R2* has been recently proposed [31] and it offers several advantages, among which is that there is no need for specialized offline software or postprocessing tools. Another advantage of a 3D multiecho Dixon sequence over 2D GRE sequences, in daily clinical practice, is that fat and iron can be simultaneously assessed for the whole liver. Further studies are nevertheless required to evaluate this interesting technique for the evaluation of hepatic iron concentration heterogeneities with MRI. 
Our study has several limitations. First, pathological correlations of iron and fat content were not available. Nevertheless, biopsies for these indications are currently rare, given the fact that non-invasive methods suffice for clinical care. The gold standard method used in this study was the SIR method, but SIR and T2* are not equivalent methods and this point could be debated. However, strong correlations between SIR and liver iron concentration have been widely demonstrated $[2 ; 12]$. Second, there was a significant difference in terms of age between patients and volunteers and the average age in the patient group was twice that of the age in the control group, which might have influenced the results. Third, only a few of our patients had a high hepatic iron overload considering that a large majority of them were included for dysmetabolic syndrome. Our results might not be applicable for high HIC, and further studies are required. Finally, we did not assess intra- and inter-reader reproducibility. However, previous reports have demonstrated the excellent reproducibility of all the methods used here $[6 ; 32]$.

\section{CONCLUSION}

This study shows that liver iron concentration varies in the liver within the same patient, and that it can be evaluated using the MR T2* relaxometry method. HIC variability increases with iron content and concentrations seem to be higher in the $\mathrm{IV}^{\text {th }}$ segment. Consequently, methods using a single ROI could place the ROI in this segment rather than, as is the case in current practice, in the right liver. 


\section{REFERENCES}

1 Quinn CT, St Pierre TG (2016) MRI Measurements of Iron Load in Transfusion-Dependent Patients: Implementation, Challenges, and Pitfalls. Pediatr Blood Cancer 63:773-780

2 Alustiza JM, Artetxe J, Castiella A et al (2004) MR quantification of hepatic iron concentration. Radiology 230:479-484

3 Henninger B, Zoller H, Rauch S et al (2015) R2* relaxometry for the quantification of hepatic iron overload: biopsy-based calibration and comparison with the literature. Rofo 187:472-479

4 Yokoo T, Yuan Q, Senegas J, Wiethoff AJ, Pedrosa I (2015) Quantitative R2* MRI of the liver with rician noise models for evaluation of hepatic iron overload: Simulation, phantom, and early clinical experience. J Magn Reson Imaging 42:1544-1559

$5 \quad$ Krafft AJ, Loeffler RB, Song R et al (2016) Does fat suppression via chemically selective saturation affect R2*-MRI for transfusional iron overload assessment? A clinical evaluation at 1.5T and 3T. Magn Reson Med 76:591-601

6 Virtanen JM, Komu ME, Parkkola RK (2008) Quantitative liver iron measurement by magnetic resonance imaging: in vitro and in vivo assessment of the liver to muscle signal intensity and the R2* methods. Magn Reson Imaging 26:1175-1182

7 Christoforidis A, Perifanis V, Spanos G et al (2009) MRI assessment of liver iron content in thalassamic patients with three different protocols: comparisons and correlations. Eur J Haematol 82:388-392

8 Verlhac S, Morel M, Bernaudin F, Bechet S, Jung C, Vasile M (2015) Liver iron overload assessment by MRI R2* relaxometry in highly transfused pediatric patients: an agreement and reproducibility study. Diagn Interv Imaging 96:259-264

9 Ibrahim el SH, Khalifa AM, Eldaly AK (2014) The influence of the analysis technique on estimating liver iron overload using magnetic resonance imaging T2* quantification. Conf Proc IEEE Eng Med Biol Soc 2014:4639-4642 Positano V, Pepe A, Santarelli MF et al (2009) Multislice multiecho T2* cardiac magnetic resonance for the detection of heterogeneous myocardial iron distribution in thalassaemia patients. NMR Biomed 22:707-715 Meloni A, Luciani A, Positano V et al (2011) Single region of interest versus multislice T2* MRI approach for the quantification of hepatic iron overload. J Magn Reson Imaging 33:348-355 Gandon Y, Olivie D, Guyader D et al (2004) Non-invasive assessment of hepatic iron stores by MRI. Lancet 363:357-362

13 Rutkauskas S, Gedrimas V, Pundzius J, Barauskas G, Basevicius A (2006) Clinical and anatomical basis for the classification of the structural parts of liver. Medicina (Kaunas) 42:98-106 Wood JC, Enriquez C, Ghugre N et al (2005) MRI R2 and R2* mapping accurately estimates hepatic iron concentration in transfusion-dependent thalassemia and sickle cell disease patients. Blood 106:1460-1465 Hussain HK, Chenevert TL, Londy FJ et al (2005) Hepatic fat fraction: MR imaging for quantitative measurement and display--early experience. Radiology 237:1048-1055 Kreeftenberg HG, Koopman BJ, Huizenga JR, van Vilsteren T, Wolthers BG, Gips CH (1984) Measurement of iron in liver biopsies--a comparison of three analytical methods. Clin Chim Acta $144: 255-262$ Ludwig J, Hashimoto E, Porayko MK, Moyer TP, Baldus
study of 447 native livers. Gastroenterology 112:882-888 Emond MJ, Bronner MP, Carlson TH, Lin M, Labbe RF, Kowdley KV (1999) Quantitative study of the variability of hepatic iron concentrations. Clin Chem 45:340-346 Ambu R, Crisponi G, Sciot R et al (1995) Uneven hepatic iron and phosphorus distribution in betathalassemia. J Hepatol 23:544-549 tissue; mapping local tissue iron concentrations with MRI [corrected]. Magn Reson Med 49:572-575 Rose C, Vandevenne P, Bourgeois E, Cambier N, Ernst O (2006) Liver iron content assessment by routine and simple magnetic resonance imaging procedure in highly transfused patients. Eur J Haematol 77:145-149 heterogeneity of liver iron and fat quantification using MRI-based multistep adaptive fitting algorithm. J Magn Reson Imaging 42:1281-1290 
Sirlin CB, Reeder SB (2010) Magnetic resonance imaging quantification of liver iron. Magn Reson Imaging Clin N Am 18:359-381, ix

24 Yu H, Shimakawa A, McKenzie CA, Brodsky E, Brittain JH, Reeder SB (2008) Multiecho water-fat separation and simultaneous R2* estimation with multifrequency fat spectrum modeling. Magn Reson Med 60:1122-1134

25 Westphalen AC, Qayyum A, Yeh BM et al (2007) Liver fat: effect of hepatic iron deposition on evaluation with opposed-phase MR imaging. Radiology 242:450-455

26 O'Regan DP, Callaghan MF, Wylezinska-Arridge M et al (2008) Liver fat content and T2*: simultaneous measurement by using breath-hold multiecho MR imaging at 3.0 T--feasibility. Radiology 247:550-557

27 Sanches-Rocha L, Serpa B, Figueiredo E, Hamerschlak N, Baroni R (2013) Comparison between multiecho T2* with and without fat saturation pulse for quantification of liver iron overload. Magn Reson Imaging 31:1704-1708

28 Meloni A, Tyszka JM, Pepe A, Wood JC (2015) Effect of inversion recovery fat suppression on hepatic R2* quantitation in transfusional siderosis. AJR Am J Roentgenol 204:625-629

29 Cassidy FH, Yokoo T, Aganovic L et al (2009) Fatty liver disease: MR imaging techniques for the detection and quantification of liver steatosis. Radiographics 29:231-260

30 Koelblinger C, Krssak M, Maresch J et al (2012) Hepatic steatosis assessment with 1H-spectroscopy and chemical shift imaging at 3.0 T before hepatic surgery: reliable enough for making clinical decisions? Eur J Radiol 81:2990-2995

31 Henninger B, Zoller H, Kannengiesser S, Zhong X, Jaschke W, Kremser C (2017) 3D Multiecho Dixon for the Evaluation of Hepatic Iron and Fat in a Clinical Setting. J Magn Reson Imaging 46:793-800 Saiviroonporn P, Viprakasit V, Sanpakit K, Wood JC, Krittayaphong R (2012) Intersite validations of the pixel-wise method for liver R2* analysis in transfusion-dependent thalassemia patients: a more accessible and affordable diagnostic technology. Hematol Oncol Stem Cell Ther 5:91-95 


\section{FIGURE LEGENDS}

Figure 1. Example of multi-ROI placement on the liver using the four slice multi-echo T2* sequence. In 1A, a segmental analysis. In 1B, a whole-liver analysis.

Figure 2. A patient with a heterogeneous deposit of iron in the liver on R2* mapping. The HIC measured within ROI 1 (placed on the fourth segment) and within ROI2 (placed on the seventh segment of the liver), as illustrated in Figure 2A, are quite different (Figure 2B): 83 $\mu \mathrm{mol} / \mathrm{g}$ versus $63 \mu \mathrm{mol} / \mathrm{g}$, respectively.

Figure 3. Distribution of R2* values for patients with HIC heterogeneities according to the SIR method. Linear regression equations and coefficients of correlation are given on the graphs according to each model used (constant offset, 3A; truncature 3B).

Figure 4. Agreement between SIR and R2* methods according to Bland and Altman plots. Mean HIC as units of $\mu \mathrm{mol} / \mathrm{g}$ is given on the abscissa and differences in SIR-R2* on the ordinate. The solid line represents the mean difference: $36 \pm 37.6 \mu \mathrm{mol} / \mathrm{g}$ and $29.4 \pm 33.6$ $\mu \mathrm{mol} / \mathrm{g}$ for the truncature (4A) and the offset models (4B), respectively. 

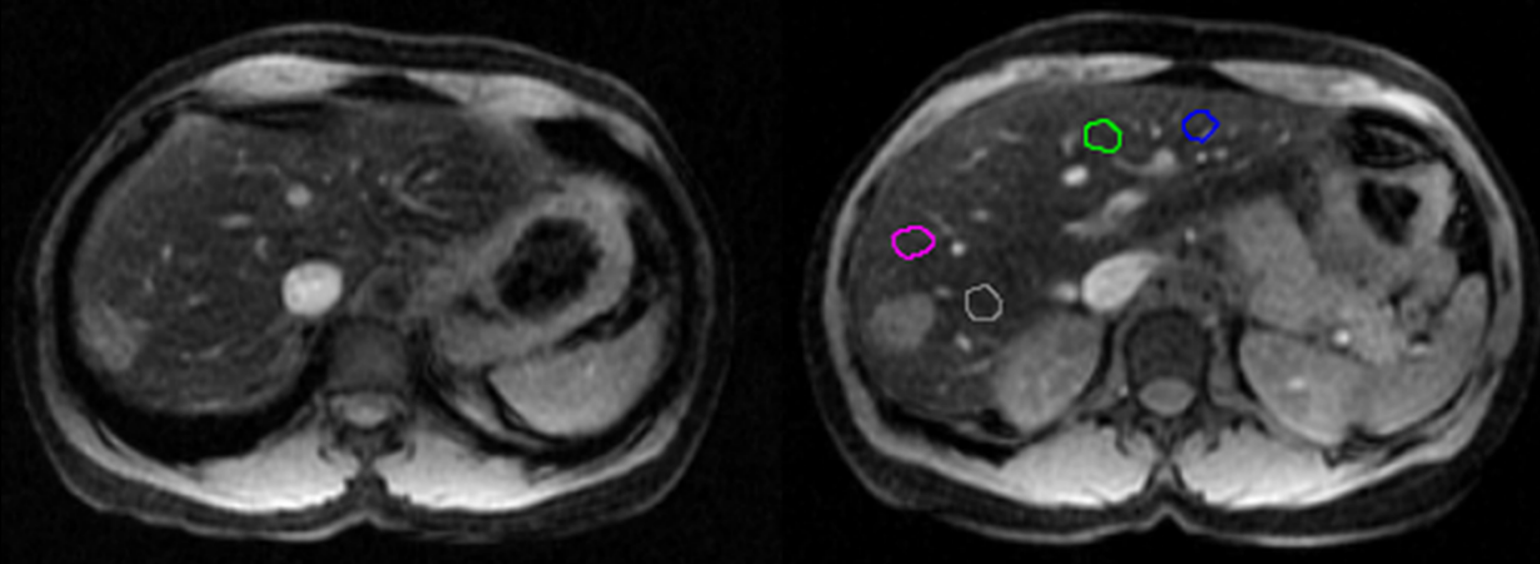

s3p4

$0.0 \mathrm{~s} 4 \mathrm{p} 4$

0.0
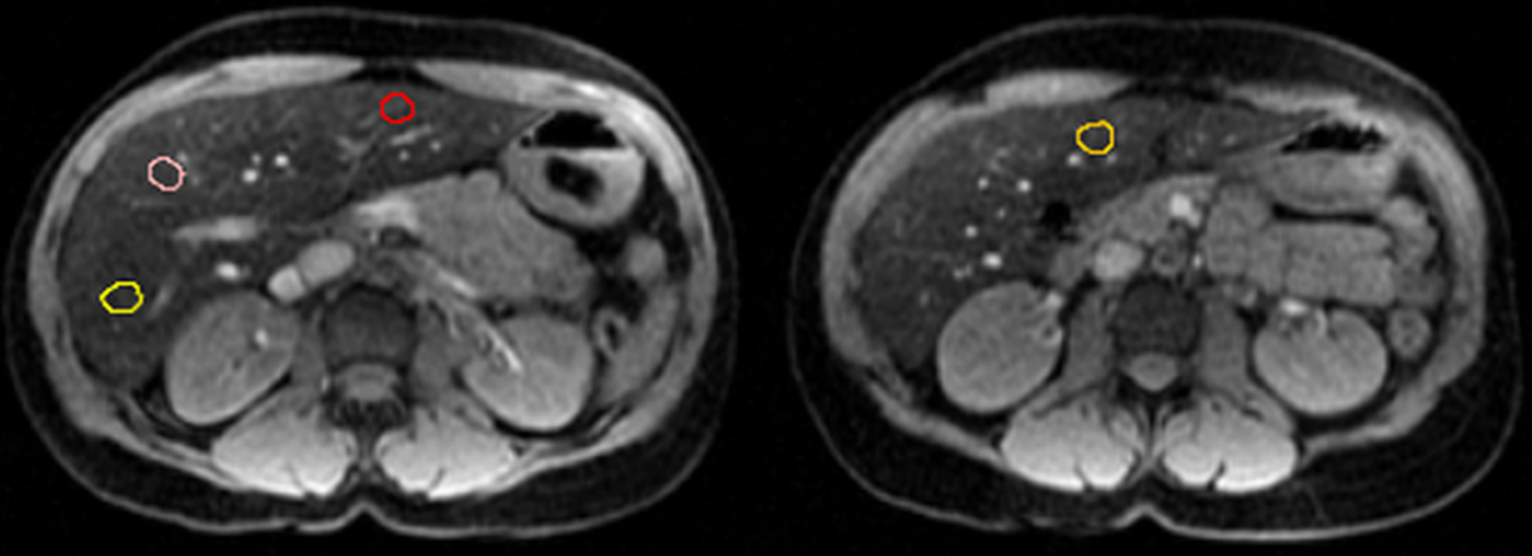

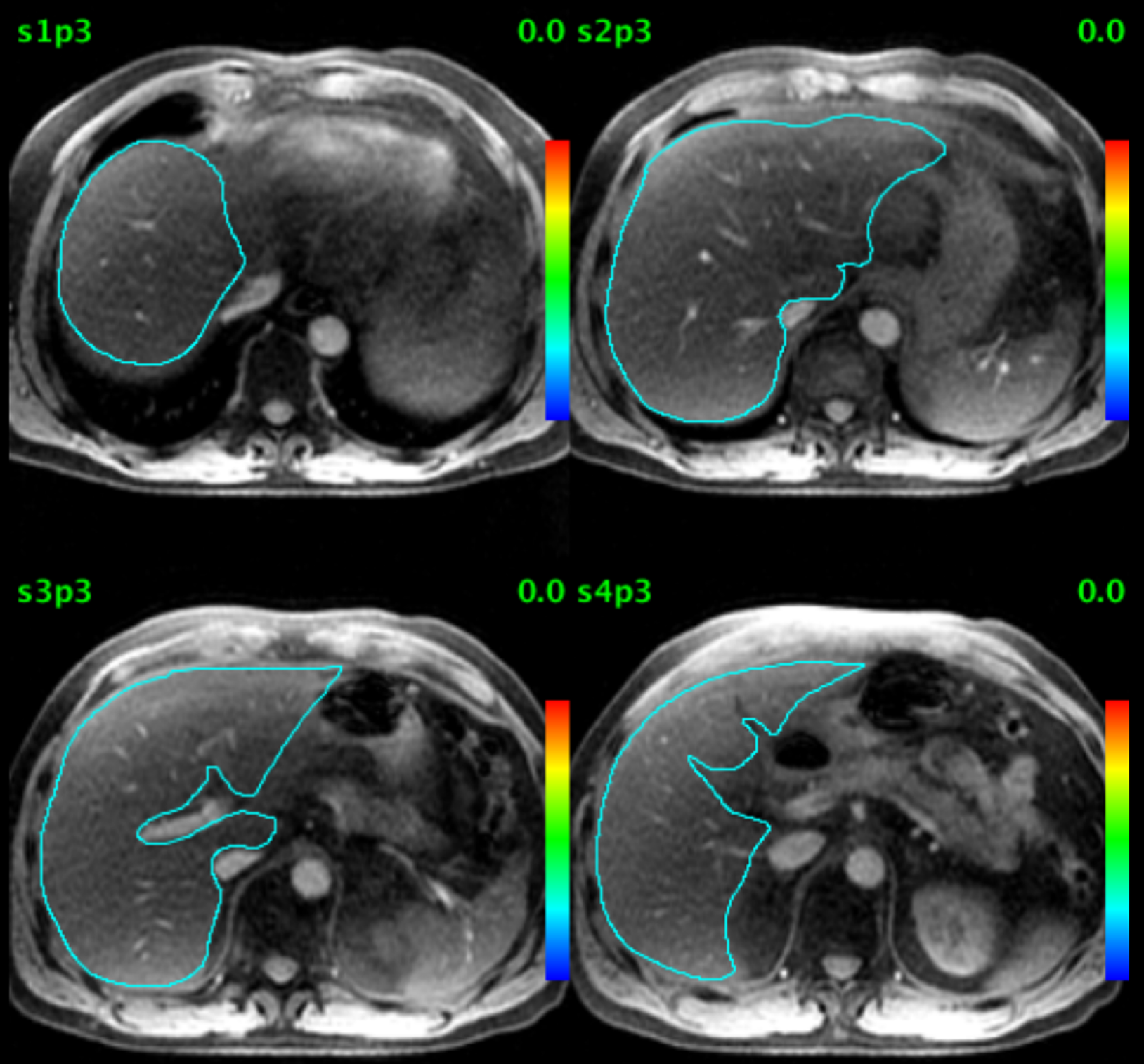


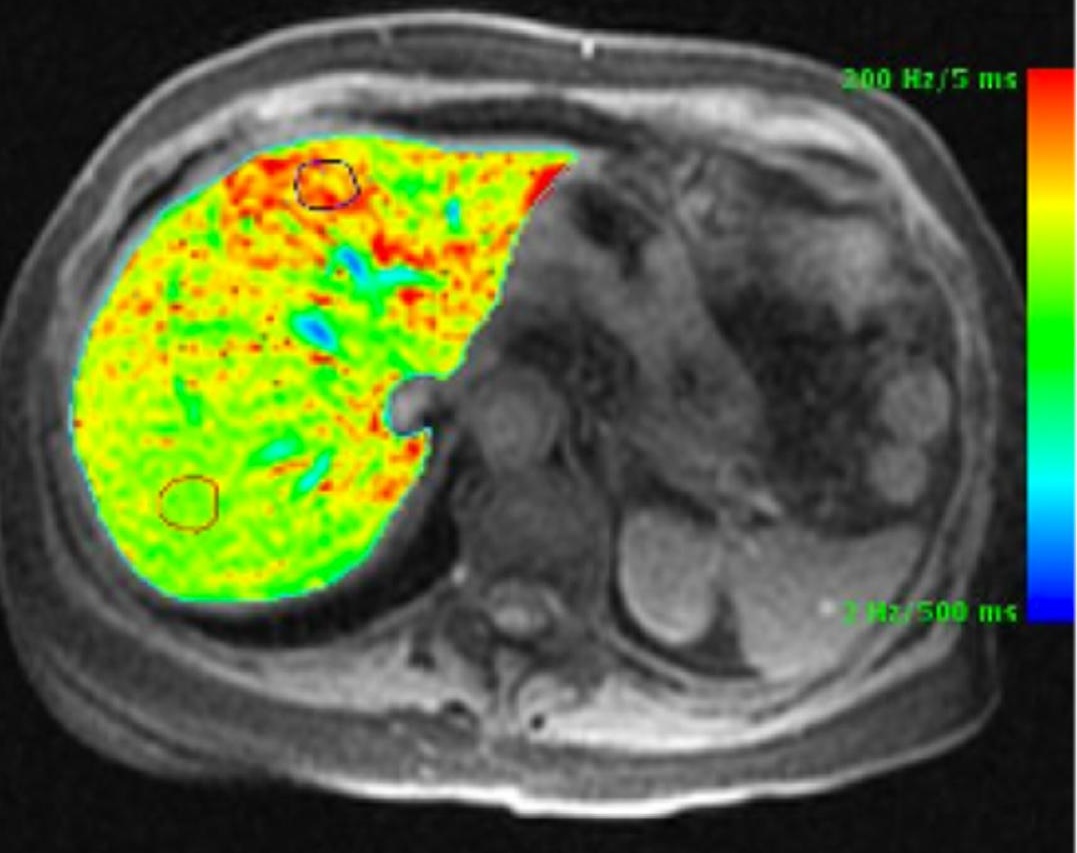




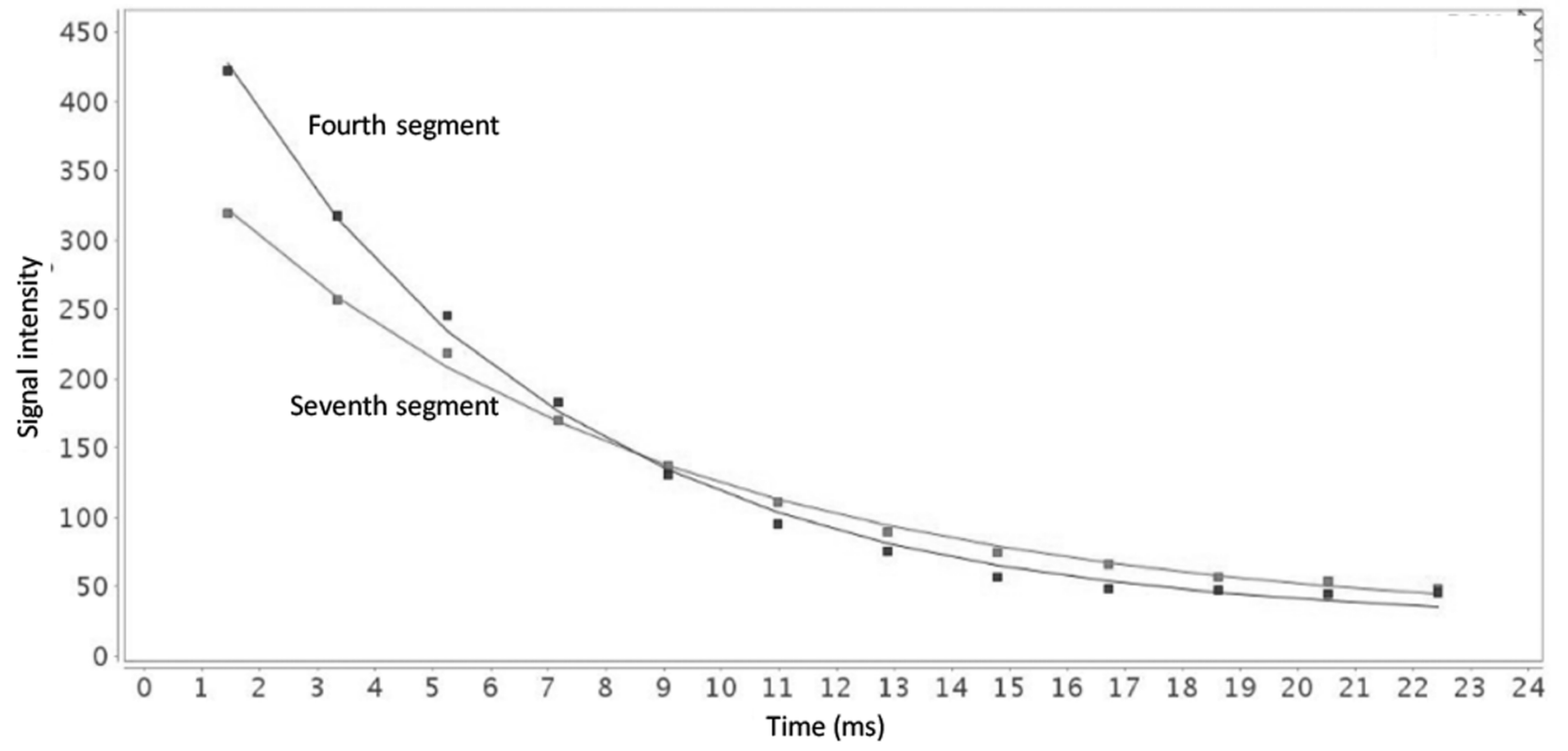




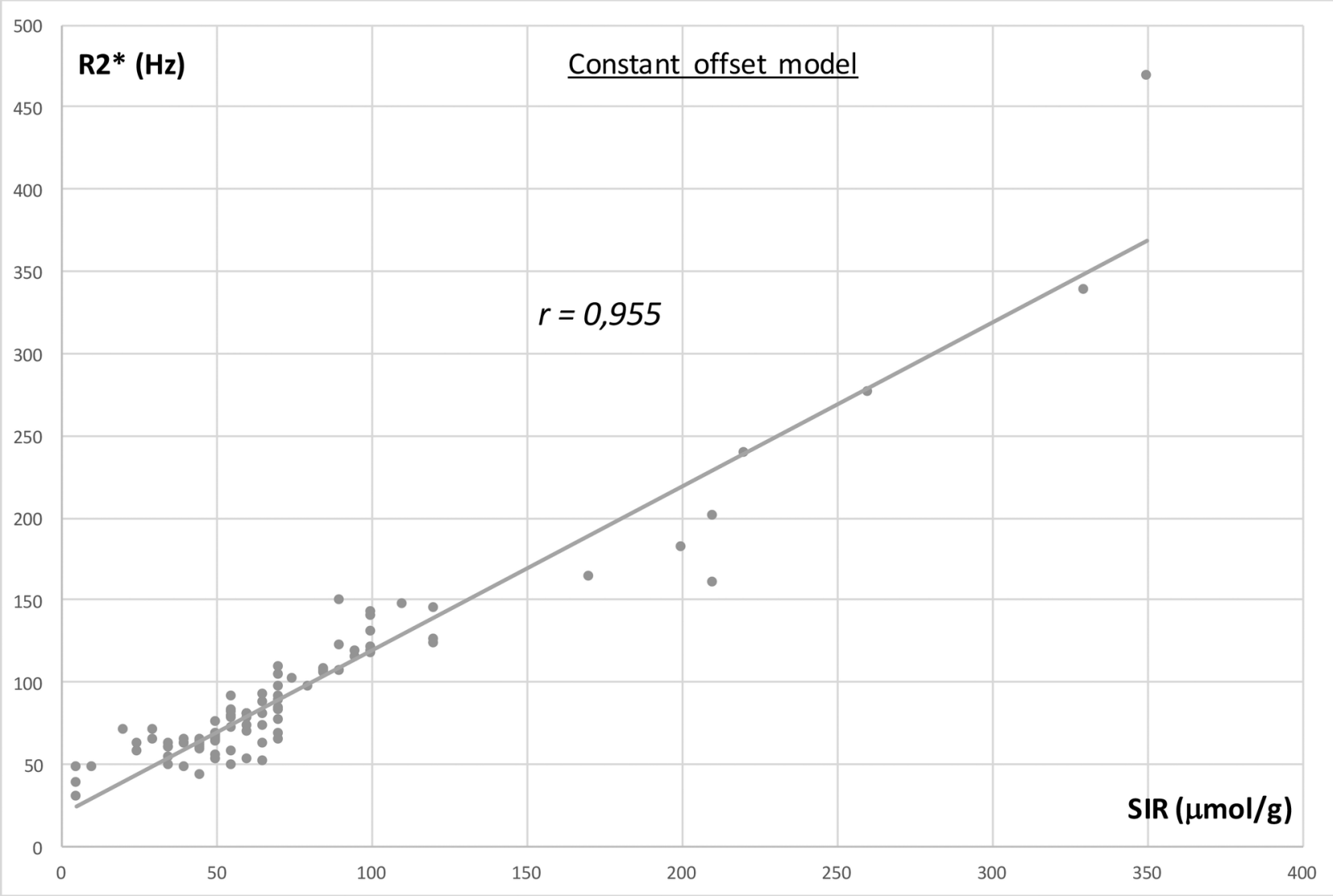




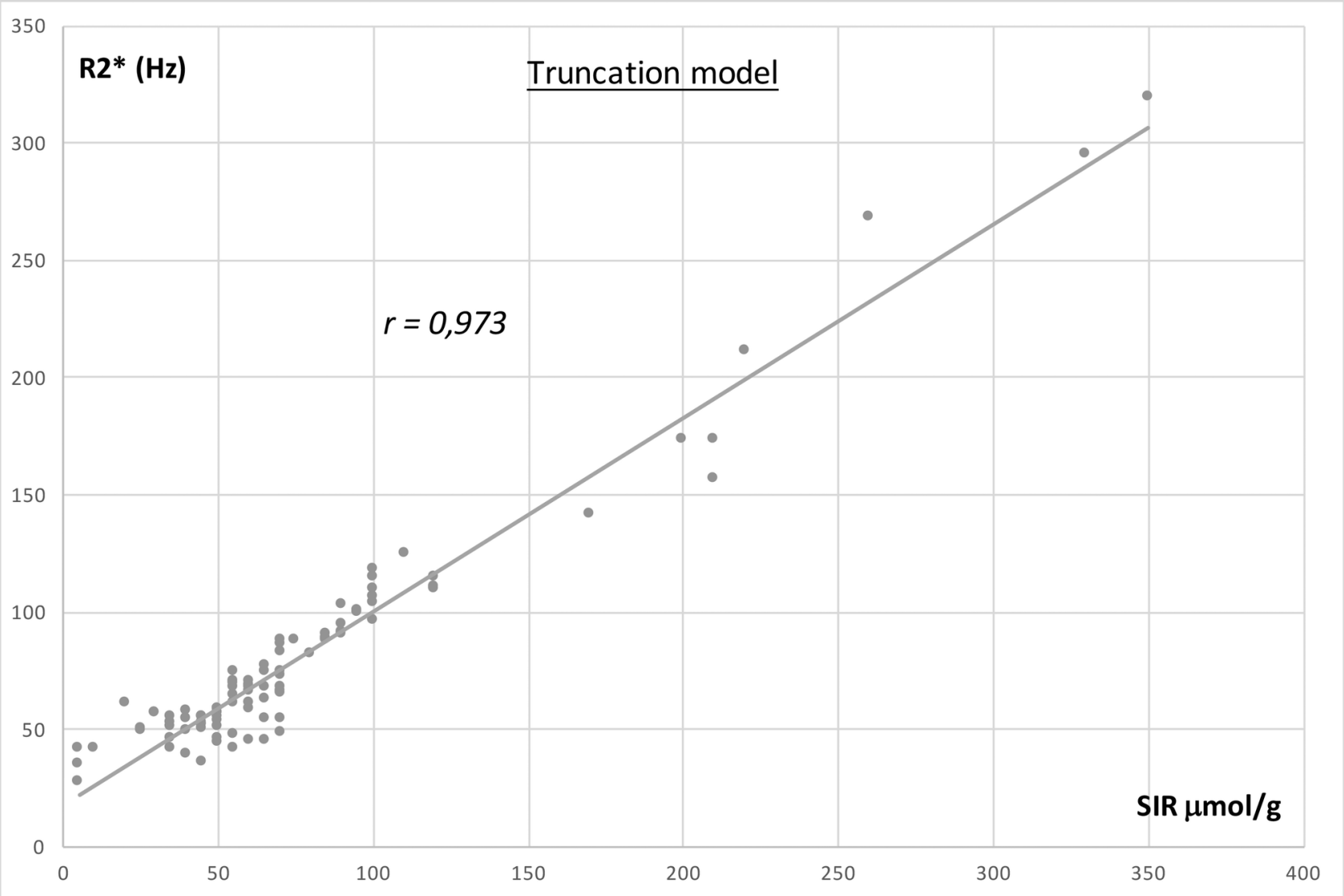




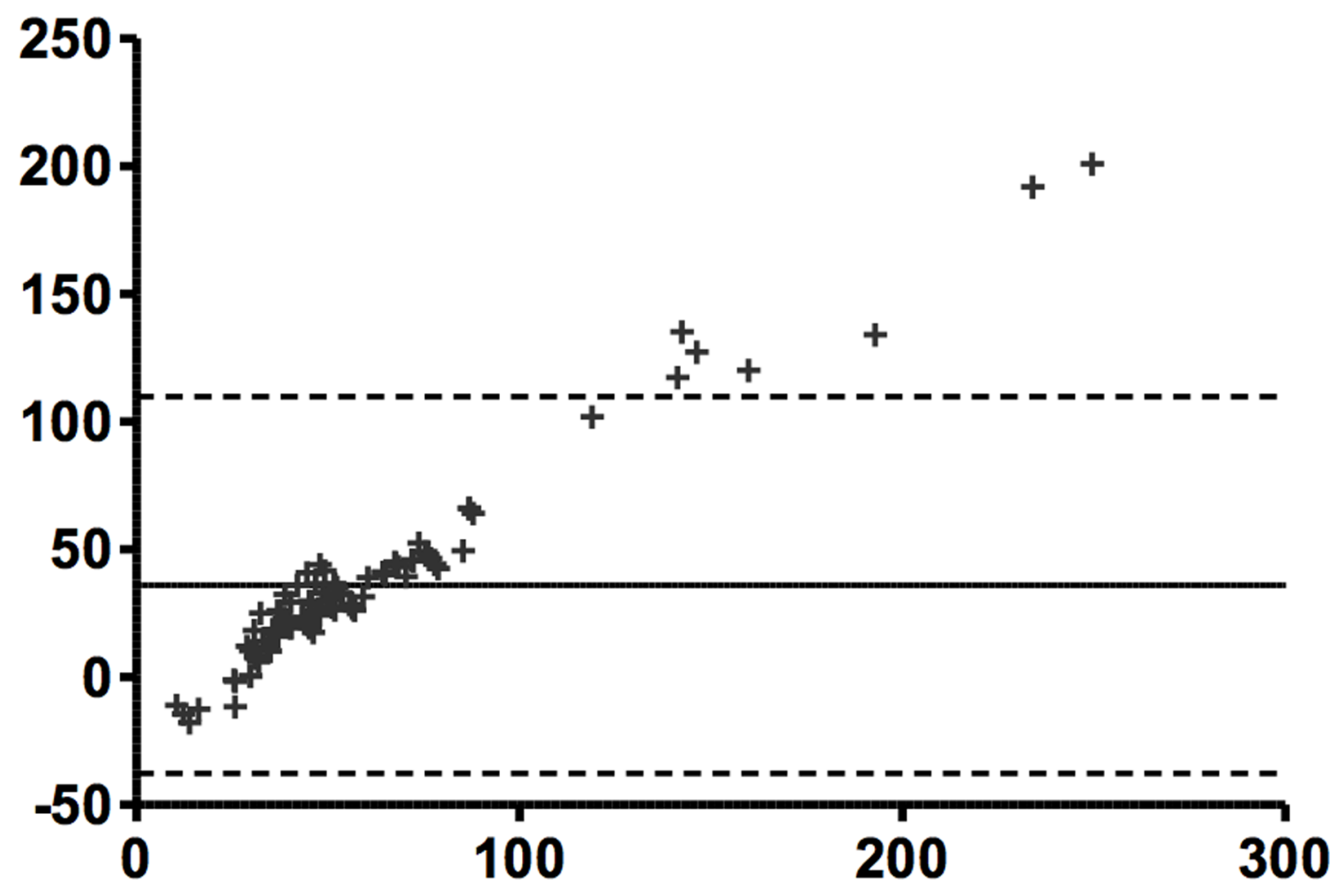


200

$100-\begin{array}{r}+ \\ + \\ ++\end{array}$

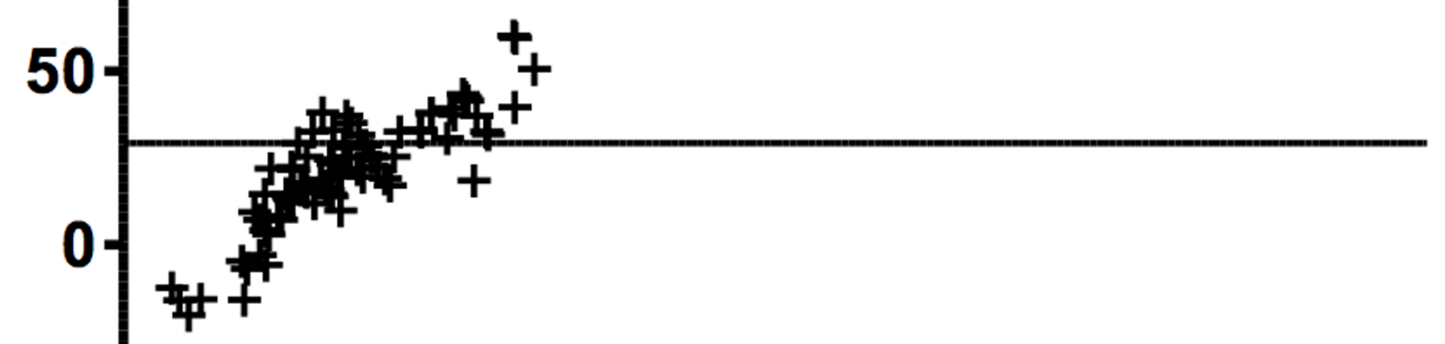


Table 1. Mean +/- SD results for the patient group $(N=94)$ using the three decay models

\begin{tabular}{llll}
\hline & SED & SEDt & COS \\
$\mathbf{R 2} *(\mathbf{H z})$ & $69.3+/-22.8$ & $80,8+/-50.7$ & $95.4+/-62.4$ \\
HIC $(\boldsymbol{\mu} \mathbf{m o l} / \mathbf{g})$ & $35.2+/-10.4$ & $44.1+/-26.1^{2}$ & $47.1+/-28.4^{1}$ \\
Difference SIR $-41.3+/-53.4$ & $32.4+/-34.8$ & $29.4+/-33.6$ \\
$\mathbf{R 2} *(\boldsymbol{\mu} \mathbf{m o l} / \mathbf{g})$ & & &
\end{tabular}

${ }^{1}$ According to the Wood calibration curve

${ }^{2}$ According to the Henninger calibration curve 
Table 2. Correlation between the SIR and the R2* relaxometry methods according to various levels of overload

$\begin{array}{lllll}\mathbf{R 2} * & \text { SIR } & & & \\ & <36 & 36-99 & >100 & \\ <36 & \mathbf{2 3} & 44 & 0 & 67 \\ 36-99 & 0 & \mathbf{1 9} & 15 & 34 \\ >100 & 0 & 0 & \mathbf{3} & 3 \\ & 23 & 63 & 18 & \mathbf{1 0 4} \\ \text { Truncation model } & & & \end{array}$

\begin{tabular}{lllll}
$\mathbf{R 2} *$ & SIR & & & \\
& $<36$ & $36-99$ & $>100$ & \\
$<36$ & $\mathbf{2 3}$ & 27 & 0 & 50 \\
$36-99$ & 0 & $\mathbf{3 6}$ & 14 & 50 \\
$>100$ & 0 & 0 & $\mathbf{4}$ & 4 \\
& 23 & 63 & 18 & $\mathbf{1 0 4}$ \\
\hline
\end{tabular}

Offset model 
Table 3; results according each liver segment.

\begin{tabular}{|c|c|c|c|c|c|}
\hline & $\begin{array}{c}\text { Volunteers } \\
\mathbf{N}=10\end{array}$ & $\begin{array}{c}\text { Patient group } \\
\qquad \mathbf{N}=\mathbf{8 6}\end{array}$ & $\begin{array}{c}\text { HIC > } \\
60 \mu \mathrm{mol} / \mathrm{g}^{1} \\
\mathrm{~N}=15\end{array}$ & $\begin{array}{c}\mathrm{HIC}> \\
100 \mu \mathrm{mol} / \mathrm{g}^{2} \\
\mathrm{~N}=18\end{array}$ & $\begin{array}{c}\text { Steatosis } \\
\quad \mathbf{N}=\mathbf{3 8}\end{array}$ \\
\hline Seg II & $24.84 *$ & $50.31 *$ & 104.27 & 96.28 & $\begin{array}{c}37.62 * \\
(-2.23 \%)\end{array}$ \\
\hline Seg III & 24.05 & $48.99 *$ & $97.39 *$ & $91.16^{*}$ & $38.02 *$ \\
\hline Seg IVa & $25.05^{*}$ & $\begin{array}{c}52.60 * \\
(+5.01 \%)\end{array}$ & $\begin{array}{c}109.93 \% \\
(+7.50 \%)\end{array}$ & $101.38 *$ & $\begin{array}{c}40.03 \% \\
(+4.03 \%)\end{array}$ \\
\hline Seg IVb & $\begin{array}{c}23.35 \% \\
(-4.73 \%)\end{array}$ & $51.16^{*}$ & 108.41 & $\begin{array}{c}101.59 \% \\
(+6.79 \%)\end{array}$ & $38.33^{*}$ \\
\hline $\operatorname{Seg} V$ & $24.05 *$ & $50.77 *$ & 107.68 & 100.04 & $38.08 *$ \\
\hline Seg VI & $23.39 *$ & $\begin{array}{c}47.33 *(- \\
5.51 \%)\end{array}$ & $92.84 *$ & $86.22 *$ & $38.19^{*}$ \\
\hline Seg VII & $25.55^{*}$ & $48.13^{*}$ & $\begin{array}{l}91.54 *(- \\
10.48 \%)\end{array}$ & $\begin{array}{l}85.21 *(- \\
10.43 \%)\end{array}$ & $38.53^{*}$ \\
\hline Seg VIII & $\begin{array}{c}25.81 * \\
(+5.30 \%)\end{array}$ & $51.46^{*}$ & 106.03 & $99.17 *$ & 39.01 \\
\hline $\begin{array}{l}\text { Mean HIC } \\
\text { multi-ROI }\end{array}$ & 24.51 & 50.09 & 102.26 & 95.13 & 38.48 \\
\hline $\begin{array}{l}\text { Mean HIC } \\
\text { single-ROI }\end{array}$ & 25.27 & 48.38 & 94.80 & 87.93 & 38 \\
\hline $\begin{array}{l}\text { Mean intra- } \\
\text { liver } S D\end{array}$ & 1.58 & 4.73 & 13.90 & 12.44 & 2,45 \\
\hline$C V(\%)$ & $6.45 \%$ & $9.44 \%$ & $13.59 \%$ & $13.08 \%$ & $6.37 \%$ \\
\hline Mean range & 5.06 & 19.08 & 50.60 & 46.07 & 12.88 \\
\hline
\end{tabular}

Mean values are presented in $\mu \mathrm{mol} / \mathrm{g}$. For each group, the lowest and the highest values (with

$\%$ of deviation from the mean HIC multi-ROI)are shown in bold. * indicates $\mathrm{p}<0.05$ using the ANOVA test. ${ }^{1}$ according to R2* method. ${ }^{2}$ according to SIR method. 
Table 4. Comparison of sub-groups with different HICs

\begin{tabular}{|c|c|c|c|c|}
\hline Sub-groups & 1 & 2 & 3 & 4 \\
\hline $\begin{array}{l}\text { Number of } \\
\text { patients }\end{array}$ & 35 & 36 & 15 & 10 \\
\hline Steatosis + & 21 & 14 & 3 & 0 \\
\hline $\begin{array}{l}\text { Mean HIC } \\
(\mu \mathrm{mol} / g)\end{array}$ & 30.23 & 47.66 & 102.26 & 24.51 \\
\hline $\begin{array}{l}\text { Mean intra-liver } \\
S D(\mu \mathrm{mol} / \mathrm{g})\end{array}$ & 2.10 & 3.47 & 13.90 & 1.58 \\
\hline CV (\%) & 6.90 & 7.28 & 13.60 & 6.40 \\
\hline $\begin{array}{l}\text { Mean range } \\
(\mu \mathrm{mol} / \mathrm{g})\end{array}$ & 9.88 & 15.11 & 50.60 & 5.06 \\
\hline
\end{tabular}

Sub-groups : $1=\mathrm{HIC}<36 \mu \mathrm{mol} / \mathrm{g} ; 2=36<\mathrm{HIC}<60 \mu \mathrm{mol} / \mathrm{g} ; 3=\mathrm{HIC}>60 \mu \mathrm{mol} / \mathrm{g} ; 4$ $=$ volunteers 